Scientific Electronic Archives

Issue ID: Sci. Elec. Arch. Vol. 15 (3)

March 2022

DOI: http://dx.doi.org/10.36560/15320221512

Article link: https://sea.ufr.edu.br/SEA/article/view/1512

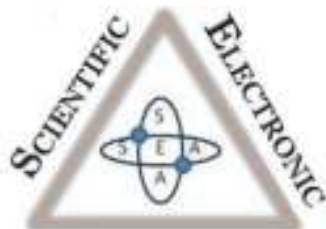

ARCHIVEs

ISSN 2316-9281

\title{
Manganês no solo e nas plantas: uma revisão
}

\author{
Manganese in soil and plants: a review
}

\author{
Corresponding author \\ Luciana Maria da Silva \\ Instituto Federal Goiano, Campus Rio Verde \\ luy.mari@hotmail.com
}

Mariana Pina da Silva Berti

Universidade Estadual de Goiás, Unidade Universitária de Ipameri

\begin{abstract}
Resumo. O manganês $(\mathrm{Mn})$ é um micronutriente de grande importância para o crescimento e desenvolvimento das plantas, desempenhando papel fundamental em diversos de seus processos vitais. Sua disponibilidade no solo depende de alguns fatores como o pH, potencial redox, presença ou ausência de matéria orgânica no solo entre outros, já sua disponibilidade para as plantas depende do estado de oxidação, sendo absorvido na forma do íon $\mathrm{Mn}^{2+}$. Atua como nutriente ou elemento tóxico no metabolismo vegetal a depender dos seus teores nos tecidos vegetais. Micronutriente extraído e exportado pelas principais plantas cultivadas, apresenta variação ampla dos teores foliares para a maioria das espécies agrícolas, sendo que sua deficiência ou excesso podem comprometer o crescimento desenvolvimento e produtividade das plantas. Desta forma, esta revisão fornece uma visão sobre o micronutriente Mn, bem como suas funçoes, sintomas de deficiência e excess. Além de abordar sobre o caminho percorrido por este elemento desde a solução do solo até sua absorção e incorporação ao metabolismo vegetal.
\end{abstract}

Palavras-chaves. Nutrição de plantas, micronutriente, dinâmica no solo-planta.

Abstract. Manganese $(\mathrm{Mn})$ is a micronutrient of great importance for the growth and development of plants, playing a fundamental role in several of their vital processes. Its availability in the soil depends on some factors such as $\mathrm{pH}$, redox potential, presence or absence of organic matter in the soil, among others, its availability to plants depends on the oxidation state, being absorbed in the form of the $\mathrm{Mn} 2+$ ion. It acts as a nutrient or toxic element in plant metabolism depending on its contents in plant tissues. Micronutrient extracted and exported by the main cultivated plants, presents wide variation in leaf contents for most agricultural species, and its deficiency or excess can compromise the growth, development and productivity of plants. Thus, this review provides an insight into the micronutrient $\mathrm{Mn}$, as well as its functions, deficiency and excess symptoms. In addition to addressing the path taken by this element from the soil solution to its absorption and incorporation into plant metabolism.

Keywords: Plant nutrition, micronutrient, soil-plant dynamics.

\section{Contextualização e Análise}

O manganês $(\mathrm{Mn})$ é 0 segundo micronutriente mais abundante em solos tropicais, perdendo apenas para o ferro $(\mathrm{Fe})$, desempenha papel importante em diversos processos vitais das plantas como fotossíntese, respiração, eliminação de espécies reativas de oxigênio (ROS), sinalização de hormônios entre outros (Alejandro et al., 2020).

Os micronutrientes apresentam importância similar aos demais nutrientes para 0 desenvolvimento das plantas. Podem ser diferenciados dos macros, através da quantidade absorvida, sendo requeridos em menor quantidade. No entanto, a sua deficiência compromete o crescimento, desenvolvimento e a produtividade das plantas (Cremonesi et al., 2019).

É importante salientar que ao estudar o elemento manganês e sua importância como micronutriente para as plantas, bem com suas funções, sintomas de deficiência e excesso é importante conhecer todo o caminho percorrido por este elemento desde a solução do solo até sua absorção e incorporação ao metabolismo vegetal. 


\section{Dinâmica do Manganês no sistema solo-planta}

A disponibilidade de manganês $(\mathrm{Mn})$ no solo depende de alguns fatores como $0 \mathrm{pH}$, potencial de oxidação-redução (redox), presença ou ausência de matéria orgânica no solo e seu equilíbrio com outros cátions como: ferro, cálcio e magnésio. Sua disponibilidade para as plantas depende do estado de oxidação (Liu et al., 2020). Com o intemperismo das rochas o Mn é liberado, sendo em sua maioria convertido rapidamente nos óxidos $\mathrm{Mn}^{3+}$ e $\mathrm{Mn}^{4+}$ (formas insolúveis, indisponíveis para as plantas), somente uma pequena porção na forma do íon $\mathrm{Mn}^{2+}$ permanece na solução do solo, sendo esta a única forma disponível para as plantas (Millaleo et al., 2010)

Em solos com $\mathrm{pH}<5,5$ (ácidos) e potencial redox alto do $\mathrm{Mn}$, os óxidos de valência +3 e +4 podem ser reduzidos a $\mathrm{Mn}^{2+}$, aumentando a concentração de $\mathrm{Mn}$ disponível para as plantas. Solos com pH de até 8, favorecem a auto-oxidação do $\mathrm{Mn}^{2+}$, deixando-o em formas não disponíveis as plantas, a adsorção do $\mathrm{Mn}$ nas partículas do solo também é favorecido devido ao $\mathrm{pH}$ alto (Alejandro et al., 2020)

Desta forma, é possível perceber que altas concentrações de $\mathrm{Mn}$ em solos ácidos pode causar toxicidade nas plantas, em contrapartida com a correção do $\mathrm{pH}$ do solo, pode ocorrer uma baixa disponibilidade de $\mathrm{Mn}$, provocando deficiência nas plantas, principalmente em solos considerados pobres. Portanto, é de suma importância manter concentrações adequadas de $\mathrm{Mn}$ no solo (Prado, 2021).

\section{Absorção, transporte e redistribuição do nutrientes}

O movimento do $\mathrm{Mn}^{2+}$ ocorre por meio dos mecanismos de difusão e interceptação radicular, caracterizado pelo movimento da solução do solo a curtas distancias, governado pela diferença de potencial e pelo crescimento da raiz em direção ao elemento, respectivamente. Desta forma, exige a aplicação dos nutrientes próximo ao sistema radicular. $O$ transporte das raízes para a parte aérea é feito na forma do íon $\mathrm{Mn}^{2+}$, via xilema, pois, o quelato de $\mathrm{Mn}$ com ácido cítrico possui uma constante de estabilidade baixa e se dissocia facilmente (Cardoso et al., 2003).

O Mn é um elemento pouco redistribuído nas plantas, sendo que o manganês das folhas apresenta pouca mobilidade, sendo pouco redistribuído, já o nutriente das raízes e caules pode ser redistribuído, porém sua importância quando ao fornecimento do elemento, pode variar conforme a espécie (Malavolta et al., 2006).

\section{Participação no metabolismo vegetal}

O manganês participa do metabolismo vegetal tanto como nutriente ou como elemento tóxico, a depender dos seus teores nos tecidos vegetais (Milaleo et al., 2010).

Uma das principais participações no metabolismo vegetal das plantas, deste micronutriente relaciona-se ao seu envolvimento no processo fotossintético, em especifico, no sistema de divisão da água no fotossistema II (PSII). Nesta etapa, conhecida como fotólise da água, um grupo de quatro átomos de $\mathrm{Mn}$ associa-se ao complexo evolutivo de oxigênio ligado a proteína do centro de reação do PSII. Este grupo de Mn acumula quatro cargas positivas, que oxidam duas moléculas de água, liberando uma molécula de $\mathrm{O}_{2}$ e quatro prótons. Desse modo, esse elemento atua nas reações que permitem a transferência de elétrons para o fotossistema II (Liu et al., 2020; Prado, 2021).

O Mn também desempenha papel como cofator, ativando mais de 30 enzimas vegetais, dentre elas: descarboxilase, desidrogenase e oxidase (Alejandro et al., 2020), atua na ativação hormonal (Schmidt et al., 2013) e na biossíntese de aminoácidos (Alejandro et al., 2020). Enzima de grande importância ativada pelo $\mathrm{Mn}$ é a nitrito redutase, através dela ocorre a redução do $\mathrm{N}$ e posteriormente sua incorporação aos esqueletos de carbono (Prado, 2021). Também apresenta ligação no processo de desintoxicação de espécies reativas de oxigênio (ERO's) (Oliveira et al., 2019a).

\section{Exigência do nutriente nas principais culturas}

A exigência nutricional das culturas aumenta de acordo com os níveis crescentes de produtividade alcançados, ao longo dos anos (Oliveira et al., 2019b). Portanto, durante o estudo das exigências nutricionais das culturas, este deve levar em conta a extração total do nutriente do solo. Uma forma simples de contabilizar esta exigência nutricional das culturas é através da fórmula: Exigência Nutricional $=$ teor de nutriente na planta inteira $\left(\%=\mathrm{g} \mathrm{kg}^{-1} \times 10\right) \times$ matéria seca da planta inteira ( $\left.\mathrm{kg} \mathrm{ha}^{-1}\right)$ (Prado, 2021).

E importância ressaltar que a faixa ótima de concentrações foliares de $\mathrm{Mn}$ na maioria das espécies agrícolas é bastante ampla, variando de $30 \mathrm{mg} \mathrm{kg}^{-1}$ a $500 \mathrm{mg} \mathrm{kg}^{-1}$ (Millaleo et al., 2010).

\section{Extração e exportação}

A extração total do $\mathrm{Mn}$ depende do seu conteúdo na planta e da quantidade ou produção de matéria seca acumulada, que varia basicamente em função do genótipo (espécie ou cultivar) e do solo.

Prado (2021) demonstrou que a extração total de $\mathrm{Mn}$ varia de acordo com a espécie, podendo variar de 130 a $5700 \mathrm{~g} \mathrm{ha}^{-1}$ para algodão e cana de açúcar, respectivamente, sendo a soja, o milho, trigo e arroz consideradas culturas intermediárias, quanto a extração com taxa de acúmulo de 401,767, 250 e $461 \mathrm{~g} \mathrm{ha}^{-1}$, respectivamente. Além disso, $0 \mathrm{Mn}$ pode ser acumulado em diferentes quantidades nas diferentes partes das plantas, porém nas diferentes espécies cultivadas, o maior acúmulo tem sido observado na parte vegetativa, incluindo caule, 
ramos e principalmente folhas (Kurihara et al., 2013; Prado, 2021).

A exportação pode ser entendida como os nutrientes removidos da lavoura no momento da colheita, através dos grãos, podendo ser contabilizado através da formula: Exportação $\left(\mathrm{kg} \mathrm{t}^{-1}\right)$ = acúmulo de nutrientes mobilizados nos grãos $(\mathrm{kg})$ $x$ matéria seca da parte exportada (t) (Prado, 2021).

Avaliando a variabilidade de macro e micronutrientes em sementes de soja Vargas et al. (2018) observaram que em média $38,95 \mathrm{~g} \mathrm{ha}^{-1}$ de manganês são exportados para cada tonelada de sementes produzida. Kurihara et al. (2013) projetando potencial produtivo de $4,0 \mathrm{t}^{-1}$ de grãos para a cultura da soja, estimam extração de $129 \mathrm{~g}$ ha $^{-1}$ pelos grãos. Na cultura do milho Oliveira et al. (2019b) avaliando a extração e exportação de micronutrientes em lavouras de alta produtividade observaram exportação de $137 \mathrm{~g} \mathrm{ha}^{-1}$ de manganês pelos grãos, o que representa $22 \%$ do total de $\mathrm{Mn}$ acumulado pelas plantas de milho. Para o milho cultivado na safrinha Simão et al. (2017) observaram exportação de $4 \mathrm{~g}$ de $\mathrm{Mn}$ para cada tonelada de grão produzido. Echer et al. (2009) avaliando absorção de nutrientes e distribuição da massa fresca e seca entre órgãos de batata-doce observaram no momento da colheita, 145 dias após o transplantio, exportação de $\mathrm{Mn}$ de $380 \mathrm{~g} \mathrm{ha}^{-1}$.

\section{Marcha de absorção}

Ponto de grande importância na Nutrição de Plantas é o conhecimento da "marcha de absorção", estudos nos quais se busca estabelecer as quantidades absorvidas de nutrientes em função do estádio fenológico da cultura ou idade da planta (Cremoanesi et al., 2019). Através do seu entendimento, torna-se possível mensurar a quantidade de nutrientes acumulada em cada órgão das plantas, de acordo com o seu período de desenvolvimento. Desta forma, torna-se possível definir em qual estádio fenológico das culturas os nutrientes são mais requeridos, auxiliando assim programas de adubação das culturas (Alves et al., 2016; Schiavon et al., 2018).

Avaliando a marcha de absorção de nutrientes em meloeiro fertirrigado, Oliveira et al. (2020), observaram que o maior acúmulo de $\mathrm{Mn}$ $\left(74,62 \mathrm{~g} \mathrm{ha}^{-1}\right)$ ocorreu aos 60 dias após o transplantio (DAT) das mudas, estes autores também observaram que o acúmulo do referido nutriente nas partes vegetativas foi superior ao acumulado nas partes reprodutivas. A maior presença deste nutriente nas partes vegetativas demonstra sua importância na fotossíntese, em especial na fotólise da água (Taiz et al., 2017).

Ludwig et al. (2018) avaliando absorção de nutrientes em cultivares de gérbera, espécie utilizada como planta ornamental, observaram que o maior acúmulo de Mn ocorreu dos 29 aos 43 dias após aclimatação das mudas, com acumulo diário de $50 \mu$ planta $^{-1}$, sendo que este ocorreu em sua maioria no período reprodutivo (66\%).
Avaliando acúmulo de macro e micronutrientes na biomassa de sorgo Cavalcante et al. (2018) observaram lento acumulo de micronutrientes até o estágio de desenvolvimento V9 até cerca de 30 dias após a emergência (DAE), sendo que o máximo acúmulo de Mn ocorreu entre os 32 e $38 \mathrm{DAE}$, atingindo valores de $500 \mathrm{~g} \mathrm{ha}^{-1}$, após esse período houve estabilização de acúmulo até o final do ciclo da cultura.

\section{Sintomatologia de deficiências e excess}

A deficiência de $\mathrm{Mn}$ ocorre em solos arenosos ou ricos em calcários e solos com pH alto, causando distúrbios nas plantas (Dziwornu et al., 2018). A principal característica da deficiência de Mn nas plantas é a presença de clorose (amarelecimento) nas folhas jovens, sendo estes sintomas mais aparentes que o de deficiência de ferro $(\mathrm{Fe})$. Entretanto, deve-se lembrar que os sintomas podem variar dependendo da espécie (Prado, 2021). A presença de necrose e crescimento atrofiado também são considerados sintomas de deficiência de Mn (Dziwornu et al., 2018). Já a toxidade de Mn pode ser identificada a partir do encarquilhamento das folhas (Mascarenhas et al., 2013).

Conforme Malavolta et al. (2000), na cultura da soja a deficiência de Mn é caracterizada pela presença de clorose internerval nas folhas novas. Além disso, os teores foliares desse nutriente se mantém baixos, entre 10 a $20 \mathrm{mg} \mathrm{kg}^{-1}$. Ferreira, (2012) avaliando a sintomatologia de deficiência nutricional na cultura do milho, observou que as plantas deficientes em $\mathrm{Mn}$ apresentaram redução da altura e clorose internerval nas folhas jovens.

$\mathrm{Na}$ cultura da cana-de-açucar também é possível observar clorose nas folhas novas, que podem ser "desfiadas" devido ao vento nos canaviais afetando desta forma, a produção final. Além disso, a deficiência de $\mathrm{Mn}$ na cultura pode reduzir a produção de compostos fenólicos e lignina componentes essenciais na produção de bioenergia, pois facilitam a combustão da biomassa vegetal (Teixeira et al., 2020).

Caracterizando as deficiências minerais de micro e macro nutrientes, através da diagnose visual, em mudas de pinhão-manso (Jatropha curcas L.) Nunes et al. (2016) observaram clorose internerval nas folhas novas, além de ausência de nervuras secundárias.

$\mathrm{O}$ excesso de $\mathrm{Mn}$ pode inibir a taxa de crescimento de brotos e raízes de forma geral e influenciar de negativamente alguns processos fisiológicos e bioquímicos das plantas (Zhao et al., 2017; Liu et al., 2020). O principal sintoma do excesso de $\mathrm{Mn}$ são manchas necróticas marrons nas folhas, devido ao alto acúmulo de $\mathrm{Mn}$ oxidado no apoplasto (Dziwornu et al., 2018).

$\mathrm{Na}$ cultura do arroz o tratamento prolongado com excesso de $\mathrm{Mn}$ em diferentes genótipos de arroz, afetou diretamente o crescimento, com 
redução do caule e o metabolismo das plantas (Dziwornu et al., 2018).

Liu et al. (2020) observaram que na cultura da soja o excesso de $\mathrm{Mn}$ acarretou em redução do crescimento refletido assim na diminuição do peso fresco das plântulas de soja e aumento de manchas marrons nas folhas.

\section{Considerações Finais}

Diante do exposto, pode se perceber que apesar de ser requerido em poucas quantidades 0 micronutriente manganês apresenta grande importância para a as culturas de forma geral, pois participa de processos vitais para as mesmas.

\section{Referências}

ALEJANDRO, S.; HÖLLER, S.; MEIER, B. PEITER, E. Manganese in plants: from acquisition to subcellular allocation. Frontiers in Plant Science, v. 11, p. 300, 2020.

ALVES, M. S.; SMIDERLE, O. J.; SOUZA, A. G.; CHAGAS, E. A.; FAGUNDES, P. R. O.; SOUZA, O. M. Crescimento e marcha de absorção de nutrientes em mudas de Khaya ivorensis. Acta Iguazu, v. 5, n. 4, p. 95-110, 2016.

CAVALCANTE, T. J.; CASTOLDI, G.; RODRIGUES, C. R.; NOGUEIRA, M. M.; ALBERT, A. M. Macro and micronutrients uptake in biomass sorghum. Pesquisa Agropecuária Tropical, v. 48, p. 364-373, 2018.

CARDOSO, E. J. B. N.; NAVARRO, R. B.; NOGUEIRA, M. A. Absorção e translocação de manganês por plantas de soja micorrizadas, sob doses crescentes deste nutriente. Revista brasileira de ciência do solo, v. 27, p. 415-423, 2003.

CREMONESI, M. V.; RAMALHO, B.; GOLFETTO, P.; KREPKI, L. S.; PAULETTI, V. Marcha de absorção, taxa de acúmulo e exportação de micronutrientes e alumínio pelo tabaco (Nicotiana tabacum L.). Revista de Ciências Agroveterinárias, v. 18, n. 1, p. 13-23, 2019.

DZIWORNU, A. K.; SHRESTHA, A.; MATTHUS, E.; ALI, B.; WU, L. B.; FREI, M. Responses of contrasting rice genotypes to excess manganese and their implications for lignin synthesis. Plant Physiology and Biochemistry, v. 123, p. 252-259, 2018.

ECHER, F. R.; DOMINATO, J. C.; CRESTE, J. E. Absorção de nutrientes e distribuição da massa fresca e seca entre órgãos de batatadoce. Horticultura brasileira, v. 27, p. 176-182, 2009.

FERREIRA, M. M. M. Sintomas de deficiência de macro e micronutrientes de plantas de milho híbrido
BRS 1010. Revista Agroambiente Online, v. 6, n. 1, p. 74-83, 2012.

KURIHARA, C. H.; VENEGAS, V. H. A.; NEVES, J. C. L.; NOVAIS, R. F. D. Acúmulo de matéria seca e nutrientes em soja, como variável do potencial produtivo. Revista Ceres, v. 60, p. 690-698, 2013.

LIU, Y.; XUE, Y.; XIE, B.; ZHU, S.; LU, X.; LIANG, C.; TIAN, J. Complex gene regulation between young and old soybean leaves in responses to manganese toxicity. Plant Physiology and Biochemistry, v. 155, p. 231-242, 2020.

LUDWIG, F.; FERNANDES, D. M.; GUERRERO, A. C.; BÔAS, R. L. V. Marcha de absorção de nutrientes em cultivares de gérbera de vaso. Horticultura Brasileira, v. 31, n. 4, 2018.

MALAVOLTA, E.; CABRAL, C.P.; LAVRES Jr., O.A.J. Efeitos do manganês sobre a soja cultivada em solo de Cerrado do triângulo mineiro. Pesquisa Agropecuária Brasileira, v. 35, p. 1629-1636, 2000. MALAVOLTA E. Manual de nutrição mineral de plantas. São Paulo: Agronômica Ceres; 2006

MASCARENHAS, H. A. A.; ESTEVES, J. A. F.; WUTKE, E. B.; RECO, P. C.; LEÃO, P. D. L. Deficiência e toxicidade visuais de nutrientes em soja. Nucleus, v. 10, n. 2, p. 281-306, 2013.

MILLALEO, R.; REYES-DÍAZ, M.; IVANOV, A. G.; MORA, M. L.; ALBERDI, M. Manganese as essential and toxic element for plants: transport, accumulation and resistance mechanisms. Journal of soil science and plant nutrition, v. 10, n. 4, p. 470481, 2010.

NUNES, A. O.; EXLER, R. B.; NUNES, F. M.; PAULILLO, L. C. Diagnose visual de deficiências minerais em mudas de pinhão manso (Jatropha curcas L.) em função de diferentes doses de macro e micronutrientes. Energia na Agricultura, v. 31, n. 3, p. 231-236, 2016.

OLIVEIRA, R. L. L.; MELLO PRADO, R.; FELISBERTO, G.; CHECCHIO, M. V.; GRATÃO, P. L. Silicon mitigates manganese deficiency stress by regulating the physiology and activity of antioxidant enzymes in sorghum plants. Journal of Soil Science and Plant Nutrition, v. 19, p. 524-34, $2019 a$.

OLIVEIRA, S. R.; ARAÚJO, J. L.; OLIVEIRA, F. S.; FÁTIMA, R. T.; ANDRADE, R. O.; FIGUEIREDO, C. F. V.; SOUSA, G. M.; NASCIMENTO, R. R. A. Marcha de absorção de nutrientes em meloeiro 'goldex'fertirrigado. Brazilian Journal of Development, v. 6, n. 3, p. 12654-12673, 2020.

OLIVEIRA, T. F.; SILVA FONSECA, I. A.; ANDRADE, G. A. V.; OLIVEIRA, V. J. B.; SOARES, M. E. P.; AQUINO, L. A. Uptake and exportation of 
micronutrients in high productivity corn fields. Revista Agroambiente Online, v. 13, p. 55-67, 2019b.

PRADO, R. M. Mineral nutrition of tropical plants. Berna: Springer Nature, 2021. 349p.

SCHIAVON, N. C.; LIMA, R. C.; AGUIAR, V. F.; SANTOS, V. K. S.; PEREIRA, G. A. M.; SILVA, E. B.; FERREIRA, E. A. Marcha de absorção de nutrientes em plantas de girassol (Helianthus annuus). Revista Cultura Agronômica, v. 27, n. 2, p. 236-250, 2018.

SCHMIDT, S. B.; PEDAS, P.; LAURSEN, K. H.; SCHJOERRING, J. K.; HUSTED, S. Latent manganese deficiency in barley can be diagnosed and remediated on the basis of chlorophyll a fluorescence measurements. Plant and Soil, v. 372, p.417-29, 2013.

SIMAO, E. D. P.; RESENDE, Á. V.; NETO, M. M. G.; BORGHI, E.; MARTINS, D. C.; VANIN, Á. Demanda de nutrientes pelo milho safrinha em função da época de semeadura e adubação. Brazilian Journal of Maize and Sorghum, v. 16, n. 3, p. 481-494, 2017.
TAIZ, L.; ZEIGER, E.; MOLLER, I. M.; MURPHY, A. Fisiologia e desenvolvimento vegetal. Artmed Editora, 2017. 888p.

TEIXEIRA, G. C. M.; ROCHA, A. M. S.; OLIVEIRA, K. S.; SANTOS SARAH, M. M.; OLIVEIRA FILHO, A. S. B.; PRADO, R. M.; PALARETTI, L. F. Silício na mitigação dos estresses por deficiência de manganês e pelo déficit hídrico em mudas prébrotadas de cana-de-açúcar. Científica, v. 48, n. 2, p. 170-187, 2020.

VARGAS, R. L.; SCHUCH, L. O.; BARROS, W. S.; RIGO, G. A.; SZARESKI, V. J.; CARVALHO, I. R.; PIMENTEL, J. R.; TROYJACK, C.; JAQUES, L. B. A.; SOUZA, V. Q. ROSA, T. C.; AUMONDE, T. Z.; PEDÓ, T. Macronutrients and micronutrients variability in soybean seeds. Journal of Agricultural Science (Toronto), v. 10, n. 4, p. 209-222, 2018.

ZHAO, J.; WANG, W.; ZHOU, H.; WANG, R.; ZHANG, P.; WANG, H.; PAN, $\quad \mathrm{X} . ; \quad \mathrm{XU}, \quad \mathrm{J}$. Manganese toxicity inhibited root growth by disrupting auxin biosynthesis and transport in Arabidopsis. Frontiers in plant science, v. 8, p. 272, 2017. 